\title{
Graft Inclusion Technique: A New Flow Reduction Procedure for High Flow Arteriovenous Fistulae
}

\author{
Takehisa Nojima, MD, $\mathrm{PhD}^{1}$ and Yasuki Motomiya, MD, $\mathrm{PhD}^{2}$
}

Objective: Flow reduction is required to preserve vascular access in cases with high flow access (HFA). We report a new flow reduction procedure, the graft inclusion technique (GIT).

Methods: The GIT procedure developed by us involves the intraluminal placement and suturing of a 4-mm polytetrafluoroethylene graft to the anastomosis and outflow tract to plicate the enlarged anastomosis and maintain lower flow volumes. Flow reduction for HFA was retrospectively assessed in a series of 25 patients (age $65 \pm 12$ years; 17 males and 8 females) to evaluate flow volume and patency rate, wherein 10 patients underwent conventional methods of flow reduction and 15 underwent GIT.

Results: Compared with preprocedure values, mean flow volume (MFV) was significantly lower after the procedure with both the conventional methods $(1,817 \mathrm{vs} .586 \mathrm{ml} / \mathrm{min}$; $\mathrm{P}<0.05)$ and the GIT $(2,262$ vs. $890 \mathrm{ml} / \mathrm{min} ; \mathrm{P}<0.05)$. An increase in MFV occurred during follow-up after conventional flow reduction (586 vs. 1,036 $\mathrm{ml} / \mathrm{min}$ ), while GIT could maintain lower MFV (890 vs. $791 \mathrm{ml} / \mathrm{min}$ ), suggesting that GIT can significantly lower MFV levels (2,262 vs. $791 \mathrm{ml} / \mathrm{min}$; $\mathrm{P}<0.05$ ) and maintain these lower MFV levels during followup. Secondary patency rate for the GIT was $100 \%$ at 1 year and $83 \%$ at 3 years.

Conclusion: The GIT may be used as an access-preserving, reliable, long-term, and stable flow-reducing procedure that does not require flow adjustment during surgery.

\footnotetext{
${ }^{1}$ Nojima Vascular Access Clinic, Kobe, Hyogo, Japan

${ }^{2}$ Suiyukai Shinryojyo, Kashihara, Nara, Japan
}

Received: December 7, 2017; Accepted: February 1, 2018 Corresponding author: Takehisa Nojima, MD, PhD. Nojima Vascular Access Clinic, Seishin Oriental Hotel 3F, Kojidai 5-6-3, Nishi-ku, Kobe, Hyogo 651-2273, Japan

Tel: +81-78-997-1055, Fax: +81-78-997-1056

E-mail: nojima@nva-c.jp

(cc) BY-NC-SA (02018 The Editorial Committee of Annals of Vascular Diseases. This article is distributed under the terms of the Creative Commons Attribution License, which permits use, distribution, and reproduction in any medium, provided the credit of the original work, a link to the license, and indication of any change are properly given, and the original work is not used for commercial purposes. Remixed or transformed contributions must be distributed under the same license as the original.
Keywords: high flow vascular access, flow reduction procedure, high output heart failure, venous hypertension, hemodialysis access-induced distal ischemia

\section{Introduction}

High flow access (HFA) for hemodailysis can occasionally lead to disorders such as venous hypertension, ${ }^{1,2}$ hemodialysis access-induced distal ischemia (HAIDI), ${ }^{3-5)}$ and high output heart failure ${ }^{6-9}$; therefore, accurate diagnosis and appropriate treatment are essential to limit subsequent complications. ${ }^{10)}$ While radical treatment for HFA involves access closure, flow reduction procedures are used to preserve access. Conventional methods of flow reduction attempted ${ }^{11)}$ till date include banding, ${ }^{2,12,13)}$ fistula plication, ${ }^{14)}$ and graft interposition. ${ }^{15)}$ However, these methods have reportedly resulted in incomplete flow reduction, ${ }^{16,17)}$ high incidence of subsequent thrombosis, ${ }^{14}$ ) and aneurysm formation, ${ }^{17)}$ suggesting that they might not be very reliable. We have therefore developed a new flow reduction procedure, the graft inclusion technique (GIT), which involves the suturing of a polytetrafluoroethylene (PTFE) graft to maintain lower flow volumes. We describe the GIT procedure and compare its results with those obtained using conventional methods.

\section{Methods}

We retrospectively reviewed data from 25 patients who had undergone flow reduction procedures for HFA in our hospital and its affiliated institutions between 2006 and 2016. From 2006 to 2007, conventional treatment with banding, fistula plication, graft plication, or graft interposition were performed in 10 patients, whereas, from 2008 to 2016, flow reduction was performed using GIT in 15 patients. Thus, patients were assigned to either the conventional or the GIT group, based on the procedure they underwent. Indications for flow reduction procedures were venous hypertension $(n=16)$, HAIDI $(n=4)$, heart failure $(n=2)$, venous hypertension $(n=1)$, heart failure $(\mathrm{n}=1)$, and only high flow $(\mathrm{n}=3)$. High flow was defined as flow rate of $\geq 1,400 \mathrm{ml} / \mathrm{min}$. Venous hypertension was 


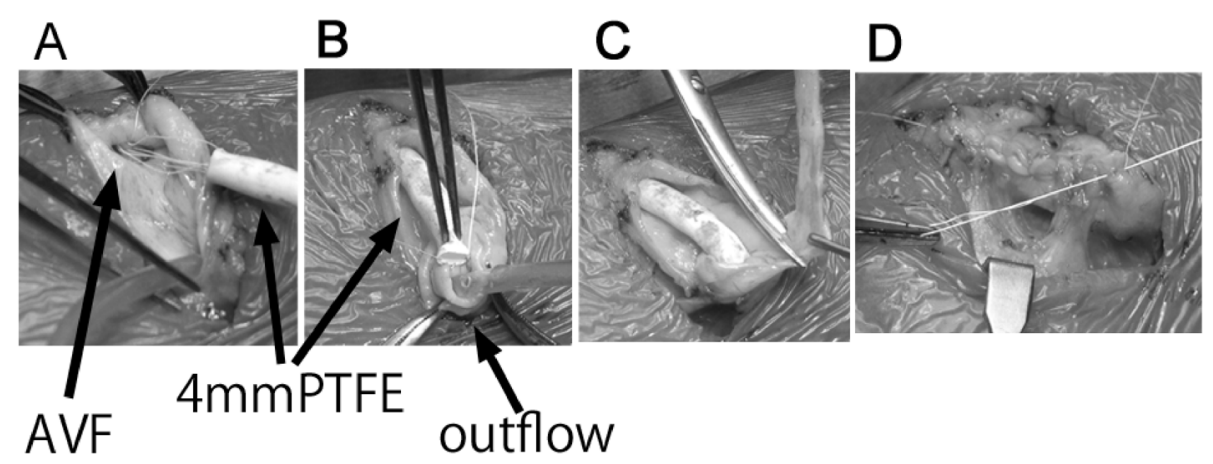

Fig. 1 Graft inclusion technique procedure. (A) The diameter of the anastomosis site is reduced to that of the graft by suturing a 4-mm polytetrafluoroethylene graft under direct vision. (B) The other end of the graft, cut at a length of approximately $4 \mathrm{~cm}$, is sutured to the outflow tract. (C) The surplus vascular wall is trimmed and closed using a running suture. (D) The graft is completely included in the autologous vascular wall.

associated with venous congestion, such as edema or ulcers in the arm and fingers. HAIDI, grade $2 b^{4)}$ or greater, was associated with intolerable pain, coldness, and absence of radial pulse with refilling after compression. High output heart failure was associated with the NYHA functional classification of grade II or more. The three patients with high flow alone underwent the procedure for the prevention of heart failure.

The number of all vascular access related surgical cases between 2006 and 2016 was 1,662, and surgery was performed by the same surgeon.

Flow volume in the brachial artery was measured prior to the procedure, postprocedure ( $\geq 3 \mathrm{~h}$ after surgery or the next day) and at follow-up (2-3 months after the surgery), using the Xario 200 (Toshiba Medial Systems, Tokyo, Japan). All procedures were performed using local anesthesia and intravenous conscious sedation.

Conventional procedures: During banding, vascular diameter was reduced by suturing a 1 - to 2 -cm wide PTFE band around the blood vessel, adjacent to the anastomosis site of the arteriovenous fistula (AVF). ${ }^{18)}$ For fistula plication, the diameter of the anastomosis site was reduced using direct purse-string suturing. For graft plication, graft diameter adjacent to the arterial side of the arteriovenous graft (AVG) anastomosis site was reduced to a width of $1-2 \mathrm{~cm}$ by continuous suturing. Graft interposition was performed by resecting a $3-7 \mathrm{~cm}$ portion of the access vessel at the AVF anastomosis site followed by interpositioning of the resected part with a $4-\mathrm{mm}$ graft. Flow volume was rarely measured during surgery, if at all, and only when conventional procedures were performed; and changes in flow volume were roughly estimated using a stethoscope or via palpitation in most patients.

GIT procedure: In the GIT procedure, a fistula vein is exposed longitudinally from the anastomosis up to approximately $4 \mathrm{~cm}$ on the outflow side. The anastomosis site of the fistula is opened longitudinally, a pneumatic tourniquet applied to the upper arm, and a 4-mm PTFE graft is placed in an intraluminal position. The use of a pneumatic tourniquet obviates the need for arterial exposure and clamping. The diameter of the anastomosis site is reduced to that of the graft by suturing the 4-mm PTFE graft under direct vision. It is essential to control the needle carefully while advancing toward the arterial wall of the anastomosis site (Fig. 1A). The other end of the graft, cut at a length of approximately $4 \mathrm{~cm}$, is sutured to the outflow tract (Fig. 1B). When the surplus vascular wall is trimmed and closed using a running suture (Fig. 1C), the graft is completely included as an autologous vascular wall (Fig. 1D). The wound is closed by releasing the pneumatic tourniquet, and intraoperative measurement or adjustment of flow volume is not required. Secondary patency rate was calculated based on the interval of time from the flow reduction procedure until the time of access abandonment.

\section{Statistical analysis}

Patient characteristics and clinical variables were analyzed using the Student's t-test and the chi-squared $\left(\chi^{2}\right)$ test. Patency rate was estimated according to the Kaplan-Meier method and compared among groups using the log-rank test. All statistical analyses were performed using EZR (Easy R) (Saitama Medical Center, Jichi Medical University), a graphical user interface for R ( $\mathrm{R}$ Foundation for Statistical Computing, Vienna, Austria).

\section{Results}

There were no significant differences in parameters such as preoperative age, gender, time after AVF creation, flow volume, morbidity due to diabetes mellitus (DM)/ hypertension (HT)/ hyperlipidemia (HL) between these two groups (Tables 1 and 2). Compared with preprocedure values, mean flow volume (MFV) was significantly lower after 
the procedure, irrespective of whether conventional methods $(1,817 \pm 597$ vs. $586 \pm 190 \mathrm{ml} / \mathrm{min} ; \mathrm{P}<0.05)$ or GIT was used $(2,262 \pm 601$ vs. $890 \pm 150 \mathrm{ml} / \mathrm{min} ; \mathrm{P}<0.05)$. While the MFV increased during follow-up after conventional flow reduction procedures (from $586 \pm 190 \mathrm{ml} / \mathrm{min}$ postprocedure to $1,036 \pm 554 \mathrm{ml} / \mathrm{min}$ during follow-up), it remained relatively unaltered after GIT (postprocedure, $890 \pm 150 \mathrm{ml} / \mathrm{min}$ vs. follow-up, $791 \pm 198 \mathrm{ml} / \mathrm{min}$ ). Thus, while conventional methods could only initially reduce flow volume, GIT could both reduce and maintain low flow volume during follow-up $(2,262 \pm 601$ vs. $791 \pm 198 \mathrm{ml} / \mathrm{min} ; \mathrm{P}<0.05)$. The average length of the graft used in GIT was $41 \pm 9.5 \mathrm{~mm}$. Patient demographic data and procedure characteristics for conventional methods and GIT are shown in Tables 1 and 2, respectively. Data on change in flow volume for all patients, from preprocedure to postprocedure, and in the follow-up period, have been graphically represented in Figs. 2A and 2B. In either group, there were no difficulties in continuing dialysis due to obstruction or poor blood flow after the procedure. After flow reduction by conventional methods, the recurrence of high flow during the follow-up was observed in both patients treated with fistula plication (patients 4 and 8 ) and in one of the three patients treated with banding (patient 5). Due to recurrent high flow, patient 8 underwent a GIT 2 years later and is identified as patient 11 in the GIT group.

In the conventional methods group, thrombosis was observed in one patient (patient 5) treated with banding and one patient (patient 9) treated with graft plication. Access was closed in three patients (patients 4, 6, and 7) in whom high flow did not recur, but they exhibited greater venous hypertension due to central vein occlusion. Flow reduction using graft interposition was well controlled in one patient (patient 10). In all three patients with high flow and HAIDI, the symptoms disappeared in the conventional methods group and did not recur during followup. Finally, seven patients with high flow and associated venous hypertension required central venous percutaneous transluminal angioplasty (PTA) to decompress venous outflow.

In patients who underwent GIT, no recurrence of high

Table 1 Characteristics of 10 patients who had undergone conventional procedures (banding, plication, and interposition)

\begin{tabular}{|c|c|c|c|c|c|c|c|c|c|c|c|c|c|}
\hline $\begin{array}{l}\text { Patient } \\
\text { No. }\end{array}$ & Age & $\mathrm{F} / \mathrm{M}$ & $\begin{array}{l}\text { Access } \\
\text { type }\end{array}$ & $\begin{array}{l}\text { Time } \\
\text { after AVF } \\
\text { (months) }\end{array}$ & $\begin{array}{l}\mathrm{DM} \\
\mathrm{HT} \\
\mathrm{HL}\end{array}$ & Indication & Procedure & $\begin{array}{l}\text { FV } \\
\text { pre }\end{array}$ & $\begin{array}{l}\mathrm{FV} \\
\text { post }\end{array}$ & $\begin{array}{l}F V \\
f / u\end{array}$ & $\begin{array}{l}\text { Ope } \\
(\min )\end{array}$ & $\begin{array}{c}f / u \\
\text { (years) }\end{array}$ & Outcome \\
\hline 1 & 62 & M & RC AVF & 59 & $\begin{array}{l}\mathrm{HT} \\
\mathrm{HL}\end{array}$ & HF/HAIDI (2b) & Banding & 2,000 & 600 & 750 & 45 & 2.5 & Death after 2.5 years \\
\hline 2 & 89 & $\mathrm{~F}$ & RC AVF & 110 & $\mathrm{HT}$ & $\mathrm{HF} / \mathrm{VH}$ & Banding & 1,780 & 370 & & 76 & 0.3 & $\begin{array}{l}\text { Central venous PTA } \\
\text { Lost to f/u }\end{array}$ \\
\hline 3 & 68 & $\mathrm{~F}$ & RC AVF & 32 & $\begin{array}{l}\text { DM } \\
\mathrm{HT}\end{array}$ & HF/HAIDI (2b) & Banding & 1,610 & 680 & 600 & 56 & 0.9 & Death after 0.9 years \\
\hline 4 & 61 & M & $\mathrm{RC} A V F$ & 125 & $\mathrm{HT}$ & $\mathrm{HF} / \mathrm{VH}$ & $\begin{array}{l}\text { Fistula } \\
\text { plication }\end{array}$ & 1,480 & 930 & 1,720 & 110 & 2.1 & $\begin{array}{l}\text { Central venous PTA } \\
\text { Central venous obstruction } \\
\text { Ligation due to VH recurred }\end{array}$ \\
\hline 5 & 50 & M & BB AVF & 81 & $\mathrm{HT}$ & $\mathrm{HF} / \mathrm{VH}$ & Banding & 3,000 & 650 & 1,470 & 52 & 5.0 & $\begin{array}{l}\text { Central venous PTA } \\
\text { Thrombosis }\end{array}$ \\
\hline 6 & 79 & $\mathrm{~F}$ & $\begin{array}{l}\text { BB loop } \\
\text { AVG }\end{array}$ & 6 & $\begin{array}{l}\text { DM } \\
\mathrm{HT}\end{array}$ & $\mathrm{HF} / \mathrm{VH}$ & $\begin{array}{c}\text { Graft } \\
\text { plication }\end{array}$ & 1,200 & 510 & 780 & 33 & 0.4 & $\begin{array}{l}\text { Central venous PTA } \\
\text { Central venous obstruction } \\
\text { Ligation due to VH recurred }\end{array}$ \\
\hline 7 & 72 & M & $\begin{array}{l}\text { BB loop } \\
\text { AVG }\end{array}$ & 2 & $\mathrm{HT}$ & $\mathrm{HF} / \mathrm{VH}$ & $\begin{array}{c}\text { Graft } \\
\text { plication }\end{array}$ & 1,200 & 300 & 400 & 108 & 0.4 & $\begin{array}{l}\text { Central venous PTA } \\
\text { Central venous obstruction } \\
\text { Ligation due to VH recurred }\end{array}$ \\
\hline 8 & 78 & $\mathrm{~F}$ & $\mathrm{RC} A V F$ & 29 & $\mathrm{HT}$ & $\mathrm{HF} / \mathrm{VH}$ & $\begin{array}{l}\text { Fistula } \\
\text { plication }\end{array}$ & 1,700 & 530 & 2,000 & 216 & 2.1 & $\begin{array}{l}\text { Central venous PTA } \\
\text { GIT was performed due to VH recurred } \\
\quad(\rightarrow \text { GIT case } 11)\end{array}$ \\
\hline 9 & 71 & M & $\begin{array}{l}\text { BB loop } \\
\text { AVG }\end{array}$ & 1 & DM & $\mathrm{HF} / \mathrm{VH}$ & $\begin{array}{c}\text { Graft } \\
\text { plication }\end{array}$ & 1,600 & 490 & 700 & 57 & 2.8 & $\begin{array}{l}\text { Central venous PTA } \\
\text { Thrombosis } \\
\text { Death after } 2.8 \text { years }\end{array}$ \\
\hline 10 & 60 & $\mathrm{~F}$ & $\mathrm{RC} A V F$ & 7 & $\mathrm{HT}$ & HF/HAIDI (2b) & Interposition & 2,600 & 800 & 900 & 78 & 0.3 & Lost to f/u \\
\hline Mean & 69.0 & & & 45.1 & & & & 1,817 & 586 & 1,036 & 83.1 & 1.65 & \\
\hline $\pm S D$ & \pm 11 & & & \pm 46 & & & & \pm 579 & \pm 190 & \pm 554 & \pm 53.1 & \pm 1.52 & \\
\hline
\end{tabular}

RC AVF: radio-cephalic arteriovenous fistula; BB AVF: brachial basilica arteriovenous fistula; BB loop AVG: brachial basilica loop arteriovenous graft; VH: venous hypertension; HF: high flow arteriovenous access; FV: flow volume; pre: preoperation; post: postoperation; ope: operation; f/u: follow-up; HAIDI: hemodialysis access-induced distal ischemia; DM: diabetes mellitus; HT: hypertension; HL: hyperlipidemia; PTA: percutaneous transluminal angioplasty 
Table 2 Characteristics of 15 patients who had undergone the graft inclusion technique (GIT)

\begin{tabular}{|c|c|c|c|c|c|c|c|c|c|c|c|c|c|c|}
\hline $\begin{array}{l}\text { Patient } \\
\text { No. }\end{array}$ & Age & $\mathrm{F} / \mathrm{M}$ & $\begin{array}{l}\text { Access } \\
\text { type }\end{array}$ & $\begin{array}{c}\text { Time } \\
\text { after AVF } \\
\text { (month) }\end{array}$ & $\begin{array}{l}\mathrm{DM} \\
\mathrm{HT} \\
\mathrm{HL}\end{array}$ & Indication & Procedure & $\begin{array}{l}\text { FV pre } \\
\text { (ml/min) }\end{array}$ & $\begin{array}{l}\text { FV post } \\
(\mathrm{ml} / \mathrm{min})\end{array}$ & $\begin{array}{l}\mathrm{FV} f / \mathrm{u} \\
(\mathrm{ml} / \mathrm{min})\end{array}$ & $\begin{array}{l}\text { Ope } \\
\text { (min) }\end{array}$ & $\begin{array}{l}\text { Graft } \\
\text { length } \\
(\mathrm{mm})\end{array}$ & $\begin{array}{c}f / u \\
\text { (years) }\end{array}$ & Outcome \\
\hline 11 & 80 & $\mathrm{~F}$ & RC AVF & 25 & $\mathrm{HT}$ & $\mathrm{HF} / \mathrm{VH}$ & GIT & 2,000 & 880 & 800 & 120 & 40 & 2.0 & $\begin{array}{l}\text { Central venous PTA } \\
\text { Death after } 2 \text { years }\end{array}$ \\
\hline 12 & 77 & $\mathrm{~F}$ & BB AVF & 48 & $\begin{array}{l}\mathrm{DM} \\
\mathrm{HT}\end{array}$ & $\mathrm{HF} / \mathrm{VH}$ & GIT & 1,800 & 780 & - & 93 & 40 & 0.1 & $\begin{array}{l}\text { Central venous PTA } \\
\text { Lost to } f / u\end{array}$ \\
\hline 13 & 37 & M & RC AVF & $=116$ & $\mathrm{HT}$ & $\mathrm{HF} / \mathrm{VH}$ & GIT & 2,570 & 950 & 1,020 & 88 & 40 & 3.6 & $\begin{array}{l}\text { Seroma, prosthesis exchange } \\
\text { to PU graft }\end{array}$ \\
\hline 14 & 40 & M & RC AVF & 43 & $\mathrm{HT}$ & $\mathrm{HF} / \mathrm{VH}$ & GIT & 2,200 & 850 & 490 & 70 & 45 & 1.8 & Thrombosis, abandonment \\
\hline 15 & 54 & M & RC AVF & 263 & $\begin{array}{l}\mathrm{DM} \\
\mathrm{HT} \\
\mathrm{HL}\end{array}$ & HF/NYHA II & GIT & 2,800 & 990 & 660 & 96 & 45 & 5.4 & $\begin{array}{l}\text { Graft PTA } \\
\text { NYHA II } \rightarrow \text { I } \\
\text { Patent }\end{array}$ \\
\hline 16 & 60 & M & RC AVF & 28 & $\mathrm{HT}$ & $\mathrm{HF}$ & GIT & 2,310 & 990 & 970 & 55 & 40 & 5.7 & Lost to $\mathrm{f} / \mathrm{u}$ \\
\hline 17 & 61 & M & RC AVF & 177 & $\mathrm{HT}$ & HF/HAIDI (2b) & GIT & 2,800 & 1,180 & 940 & 104 & 50 & 2.6 & $\begin{array}{l}\text { Infection of a cannulation site, } \\
\text { abandonment }\end{array}$ \\
\hline 18 & 55 & M & BB AVF & 59 & $\mathrm{HT}$ & $\mathrm{HF} / \mathrm{VH}$ & GIT & 1,470 & 950 & 610 & 135 & 70 & 5.3 & $\begin{array}{l}\text { Central venous PTA } \\
\text { Graft PTA } \\
\text { Patent }\end{array}$ \\
\hline 19 & 83 & M & RC AVF & 126 & $\begin{array}{l}\mathrm{DM} \\
\mathrm{HT} \\
\mathrm{HL}\end{array}$ & $\mathrm{HF} / \mathrm{VH}$ & GIT & 1,420 & 590 & 400 & 58 & 30 & 3.0 & $\begin{array}{l}\text { Central venous PTA } \\
\text { Graft PTA } \\
\text { Patent }\end{array}$ \\
\hline 20 & 55 & M & BB AVF & 83 & $\begin{array}{l}\mathrm{HT} \\
\mathrm{HL}\end{array}$ & $\mathrm{HF}$ & GIT & 2,200 & 860 & 740 & 90 & 35 & 3.8 & $\begin{array}{l}\text { Graft PTA } \\
\text { Patent }\end{array}$ \\
\hline 21 & 64 & M & RC AVF & 243 & $\mathrm{HT}$ & $\begin{array}{c}\text { HF/VH } \\
\text { NYHA II }\end{array}$ & GIT & 3,610 & 720 & 920 & 107 & 40 & 3.3 & $\begin{array}{l}\text { Central venous PTA } \\
\text { Graft PTA } \\
\text { NYHA II } \rightarrow 1 \\
\text { Patent }\end{array}$ \\
\hline 22 & 78 & M & BB AVF & 122 & $\begin{array}{l}\mathrm{HT} \\
\mathrm{HL}\end{array}$ & $\mathrm{HF} / \mathrm{VH}$ & GIT & 1,580 & 920 & 880 & 101 & 35 & 3.5 & $\begin{array}{l}\text { Central venous PTA } \\
\text { Patent }\end{array}$ \\
\hline 23 & 59 & $\mathrm{~F}$ & RC AVF & 43 & $\mathrm{HT}$ & $\mathrm{HF}$ & GIT & 1,860 & 750 & - & 61 & 35 & 0.1 & Lost to $\mathrm{f} / \mathrm{u}$ \\
\hline 24 & 64 & M & RC AVF & 27 & $\mathrm{HT}$ & $\mathrm{HF} / \mathrm{VH}$ & GIT & 2,720 & 830 & 880 & 63 & 35 & 0.8 & $\begin{array}{l}\text { Central venous PTA } \\
\text { Lost to f/u }\end{array}$ \\
\hline 25 & 71 & $M$ & BB AVF & 67 & $\begin{array}{l}\mathrm{DM} \\
\mathrm{HT} \\
\mathrm{HL}\end{array}$ & HF/NYHA II & GIT & 2,600 & 1,110 & 980 & 118 & 35 & 1.8 & $\begin{array}{l}\text { NYHA } \| \rightarrow I \\
\text { Patent }\end{array}$ \\
\hline Mean & 61.9 & & & 98.1 & & & & 2,262 & 890 & 791 & 90.6 & 41.0 & 2.97 & \\
\hline$\pm \mathrm{SD}$ & \pm 13 & & & \pm 76 & & & & \pm 601 & \pm 150 & \pm 198 & \pm 24.7 & \pm 9.5 & \pm 1.71 & \\
\hline
\end{tabular}

RC AVF: radio-cephalic arteriovenous fistula; BB AVF: brachial basilica arteriovenous fistula; VH: venous hypertension; HF: high flow arteriovenous access; FV: flow volume; pre: preoperation; post: postoperation; ope: operation; f/u: follow-up; PU: polyurethane; HAIDI: hemodialysis access-induced distal ischemia; DM: diabetes mellitus; HT: hypertension; HL: hyperlipidemia; PTA: percutaneous transluminal angioplasty

\section{A: conventional methods}

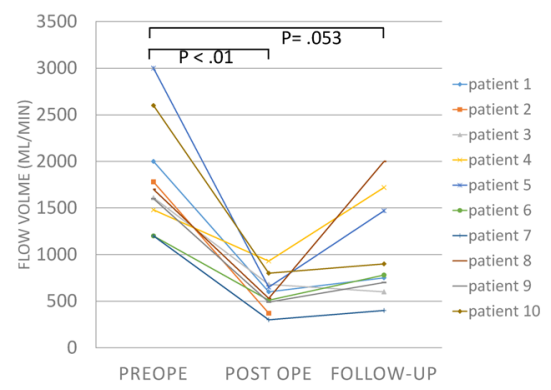

B: Graft Inclusion Technique

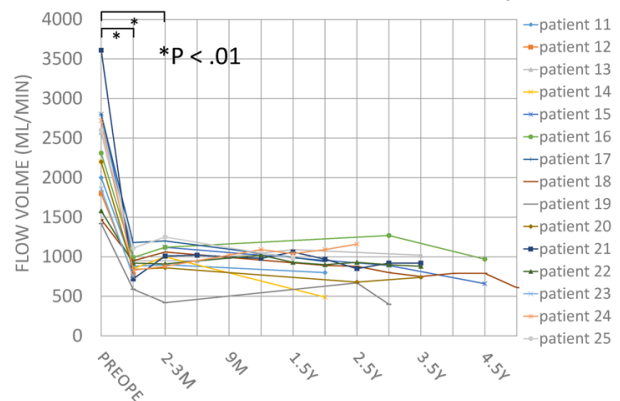

Fig. 2 Changes in flow volume in all patients. (A) Conventional method and (B) graft inclusion technique. 
flow was observed during follow-up. Moreover, symptoms generally associated with venous hypertension disappeared in all patients, except in patient 13. Patient 13 developed a seroma that required graft replacement. The novel polyurethane (PU) graft lead to an increase in graft diameter from 4 to $5 \mathrm{~mm}$ and the recurrence of edema due to a flow volume increase above $2,000 \mathrm{ml} / \mathrm{min}$. The diameter of the PU graft was reduced by plication to approximately $4 \mathrm{~mm}$, which led to the subsequent improvement in symptoms. In one patient with HAIDI (patient 17), the symptoms disappeared postoperatively; however, the access had to be abandoned due to cannulation site infection. Nevertheless, the infection did not progress to the GIT site. In the follow-up period, a graft PTA was required in five patients (patients 15, 18, 19, 20, and 21) due to venous or arterial anastomotic stenosis. The graft was occluded in two patients (patients 18 and 19), but recanalization could be achieved in both. Central venous PTA to decompress venous outflow was required in seven of the nine patients with venous hypertension. Postprocedure, all three patients with high output heart failure and categorized as a NYHA functional classification II (patients 15, 21, and 25) improved to NYHA I.

The secondary patency rate after conventional methods and GIT at 1 year was $75.0 \%$ and $100 \%$, respectively, and was $45.0 \%$ and $83.1 \%$ after 3 years, respectively. The overall survival rate for conventional methods and GIT at 1 year was $83.3 \%$ and $100 \%$, respectively, and was $22.2 \%$ and $81.8 \%$, at 3 years, respectively. No additional antiplatelet agents or anticoagulants were required after surgery in either group.

\section{Discussion}

Venous hypertension is a condition wherein venous congestion is caused by an imbalance between flow volume through the access and vascular resistance of the venous outflow tract. Therefore, reduction in flow and/or resistance of venous outflow is essential for treatment. HAIDI is a condition wherein arterial ischemia is caused by an imbalance between flow volume and vascular resistance in the peripheral artery at the anastomosis site and loss of loco-regional pressure.5) Therefore, flow reduction and/or reconstruction of the arterial flow are essential for treatment. Finally, high output heart failure is a condition wherein cardiac volume overload occurs due to high access flow, and flow reduction and/or heart failure treatment are essential for effective management. Taken together, the above statements imply that flow reduction is crucial for the treatment for venous hypertension, HAIDI, and high output heart failure associated with HFA.

Flow reduction in HFA has been performed using various surgical methods such as banding, $, 2,12,13,16,17)$ fistula plication, ${ }^{14)}$ and graft interposition. ${ }^{15)}$ However, intraoperative flow control is difficult during banding ${ }^{17)}$ or plication ${ }^{18)}$ and while thrombosis may occur if the banding or plication is too tight, high flow may persist if it is too loose. Graft interposition is an easy approach to reduce flow; however, the use of a graft is associated with certain disadvantages such as graft infestion, seroma and surgical invasion. ${ }^{19)}$ With conventional methods, the dilated anastomosis is retained, and the mean blood pressure is higher than before surgery at the anastomosis site, which may cause the recurrence of high flow or aneurysm formation at the anastomosis site. ${ }^{20)}$ Moreover, even though various methods have been introduced for improving banding, ${ }^{18,21-24)}$ the period during which the access functions effectively after surgery is not very long that recurrence within 1 year after surgery was more than half. ${ }^{13,16)}$

Flow reducing procedures being currently used include revision using distal inflow (RUDI), ${ }^{25)}$ distal revascularization and interval ligation (DRIL), ${ }^{26)}$ proximal radial artery ligation (PRAL), ${ }^{27)}$ and transposition of radial artery (TRA). ${ }^{28)}$ In these reports, DRIL, RUDI, or TRA treatments for HFA are performed in patients with brachialartery-based AVFs and are not really useful for forearm fistulas. In our study, 10 of 15 cases in the GIT group had radio-cephalic AVFs; this high percentage probably resulted from the long duration since AVF onset (mean duration: 100 months). The GIT can be used on any fistula location, even in the forearm or the elbow. PRAL has been reported to be a simple and effective method for achieving good flow reduction ${ }^{27)}$ and can be performed both in distal fistulae and radio-cephalic AVFs. However, DRIL or PRAL procedures require the native artery to be ligated, and perfusion to the forearm and hand are dependent on a bypass conduit or potential collaterals. ${ }^{29)}$

In cases of HAIDI, many reports describe DRIL as the standard procedure that provides both good patency rates and low complication frequency. ${ }^{29,30)}$

The GIT concept aims to reduce flow volume by suturing a 4-mm PTFE graft to the anastomosis and outflow tract in the intraluminal position; the enlarged anastomosis can then plicate the graft diameter and maintain reduced flow volume. Importantly, GIT reuses the previous anastomosis site and does not require a new anastomosis. The reduction in anastomosis diameter is dependent on graft size and does not subsequently expand after surgery, thereby avoiding aneurysm formation and recurrence of high flow. This simple and easy procedure does not require adjustment of flow volume during surgery. The mean reduction in flow rate is $39 \%$ with minimal variation in postoperative flow rate, leading to a reliable flow reduction. The PTFE graft used in GIT is short and completely covered by the autologous vein, which contributes to hemostasis, shorter surgical time, and lower infection 

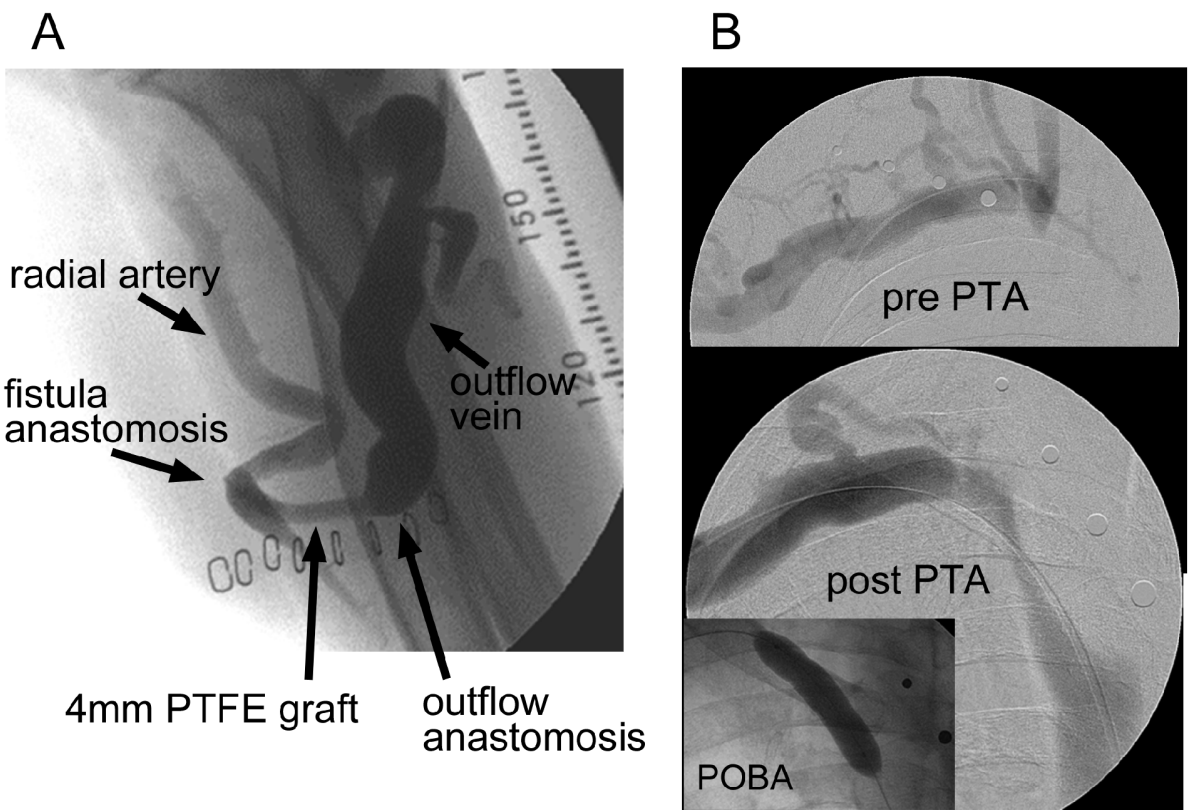

Fig. 3 Postoperative angiography for graft inclusion technique (GIT). (A) Postoperative angiography in a patient who had undergone GIT. The diameter of the outflow tract vein is usually sufficiently wide and stenosis is unlikely to occur at the outflow anastomosis site, thereby contributing to longer patency. (B) Percutaneous transluminal angioplasty in the central vein was performed in patients with venous hypertension.

risk. The mean surgical time in our study was $90.6 \mathrm{~min}$. The secondary patency rate in GIT patients who could be followed up was $100 \%$ after 1 year and $83.1 \%$ after 3 years; therefore, longer patency was obtained after GIT, compared with the conventional method. Generally, using a graft is associated with a risk of stenosis in the outflow tract; however, with GIT, as the diameter of the outflow tract is usually wide enough, stenosis is unlikely to occur at the outflow anastomosis, which then translates to longer patency (Fig. 3A).

In our facility, the first instance of GIT was attempted because it was difficult to expose vessels, even though the procedure was initially intended to be banding. It is possible to conceive of a method of flow reduction by inserting the graft into the vessel under such circumstances, and since this case in 2008, GIT was performed in all adaptive cases for flow reduction.

According to the Hagen-Poiseuille law that describes blood flow dynamics, ${ }^{10)}$ flow volume is proportional to the fourth power of the diameter of the blood vessel and to the first power of its length. Hence, a decrease in the diameter of the graft has a greater effect than an increase in length. Thus, for flow reduction using GIT, it is important to use the 4-mm diameter graft rather than increasing graft length. Among the GIT cases presented, the mean length of the grafts was $41 \mathrm{~mm}$, which led to a mean flow reduction rate of $39 \%$, demonstrating the efficacy of this technique even if shorter grafts are used (Table 2).
Patient 13 developed a seroma requiring the initial graft to be replaced with a PU graft. However, as the new graft had a diameter of $5 \mathrm{~mm}$, graft plication was subsequently necessary. Although the incidence rate of seroma associated with the use of PU grafts is low, we think that the PU graft is not suitable for GIT due to its large diameter.

Venous hypertension usually occurs in patients due to central venous stenosis. ${ }^{1)}$ In this series, all seven patients with venous hypertension had been treated using conventional methods, and seven of the nine patients who had initially undergone GIT eventually needed PTA of the central vein (Fig. 3B), which improved the symptoms of venous hypertension.

In this series, three patients underwent flow reduction due to high flow alone and were operated on to prevent heart failure. However, the preventive effect of flow reduction on heart failure has not yet been confirmed. $\left.{ }^{6}\right) \mathrm{A}$ prospective study has reported that flow volumes greater than $21 /$ min were strongly correlated with the occurrence of high output heart failure. ${ }^{8)}$ Thus, according to the high predictive power of the study mentioned above, it is possible that flow reduction prevented potential heart failure in two of the three patients in our study who had a flow volume greater than $21 / \mathrm{min}$.

As calcification of the anastomosis site was observed in more than half of the patients who underwent GIT, we recommend that an endarterectomy be performed along with GIT. 
The limitations of the present study include the small population size, the fact that this is a retrospective analysis of data from a single center and the inability to conform a preventive effect of flow reduction for HFA on heart failure. Further studies are required to confirm the conclusions presented here.

\section{Conclusion}

GIT is a relatively new flow reduction procedure that can be used for the treatment of HFA associated conditions such as venous hypertension, HAIDI, and high output heart failure. We believe that GIT can yield an accesspreserving, reliable, long-term, and stable flow-reducing effect without the need for flow volume adjustment during surgery.

\section{Disclosure Statement}

All authors have no conflicts of interest.

\section{Additional Remarks}

Part of this work was presented at the Dialysis Access Symposium in 2017, Japan, October 20, 2017.

\section{Author Contributions}

Study conception: TN

Data collection: TN

Writing: TN

Critical review and revision: all authors

Final approval of the article: all authors

\section{References}

1) Georgakarakos EI, Kapoulas KC, Georgiadis GS, et al. An overview of the hemodynamic aspects of the blood flow in the venous outflow tract of the arteriovenous fistula. J Vasc Access 2012; 13: 271-8.

2) Kanno T, Kamijo Y, Hashimoto K, et al. Outcomes of blood flow suppression methods of treating high flow access in hemodialysis patients with arteriovenous fistula. J Vasc Access 2015; 16 Suppl 1: S28-33.

3) Tordoir JHM, Dammers R, van der Sande FM. Upper extremity ischemia and hemodialysis vascular access. Eur J Vasc Endovasc Surg 2004; 27: 1-5.

4) Vaes RHD, Tordoir JH, Scheltinga MR. Blood flow dynamics in patients with hemodialysis access-induced hand ischemia. J Vasc Surg 2013; 58: 446-51.e1.

5) Scheltinga MR, van Hoek F, Bruijninckx CMA. Time of onset in haemodialysis access-induced distal ischaemia (HAIDI) is related to the access type. Nephrol Dial Transplant 2009; 24 : 3198-204.

6) Basile C, Lomonte C. The complex relationship among ar- teriovenous access, heart, and circulation. Semin Dial 2018; 31: 15-20.

7) Anderson CB, Codd JR, Graff RA, et al. Cardiac failure and upper extremity arteriovenous dialysis fistulas. Case reports and a review of the literature. Arch Intern Med 1976; 136: 292-7.

8) Basile C, Lomonte C, Vernaglione L, et al. The relationship between the flow of arteriovenous fistula and cardiac output in haemodialysis patients. Nephrol Dial Transplant 2008; 23: 282-7.

9) Bourquelot P. Access flow reduction for cardiac failure. J Vasc Access 2016; 17 Suppl 1: S60-3.

10) McGrogan DG, Maxwell AP, Khawaja AZ, et al. Current tools for prediction of arteriovenous fistula outcomes. Clin Kidney J 2015; 8: 282-9.

11) Padberg FTJ Jr, Calligaro KD, Sidawy AN. Complications of arteriovenous hemodialysis access: recognition and management. J Vasc Surg 2008; 48 Suppl: S55-80.

12) Anderson CB, Groce MA. Banding of arteriovenous dialysis fistulas to correct high-output cardiac failure. Surgery 1975; 78: 552-4.

13) van Hoek F, Scheltinga M, Luirink M, et al. Banding of hemodialysis access to treat hand ischemia or cardiac overload. Semin Dial 2009; 22: 204-8.

14) Odland MD, Kelly PH, Ney AL, et al. Management of dialysis-associated steal syndrome complicating upper extremity arteriovenous fistulas: use of intraoperative digital photoplethysmography. Surgery 1991; 110: 664-70; discussion, 669-70.

15) Chemla ES, Morsy M, Anderson L, et al. Inflow reduction by distalization of anastomosis treats efficiently high-inflow high-cardiac output vascular access for hemodialysis. Semin Dial 2007; 20: 68-72.

16) Vaes RHD, Wouda R, van Loon M, et al. Effectiveness of surgical banding for high flow in brachial artery-based hemodialysis vascular access. J Vasc Surg 2015; 61: 762-6.

17) Mallios A, Lucas Iii J, Jennings W. A mechanism of banding failure in excessively dilated fistulas. J Vasc Access 2017; Aug 2. [Epub ahead of print]

18) Zanow J, Petzold K, Petzold M, et al. Flow reduction in highflow arteriovenous access using intraoperative flow monitoring. J Vasc Surg 2006; 44: 1273-8.

19) Kim SM, Min S-K, Ahn S, et al. How to treat arteriovenous graft infection: total versus partial graft excision. J Vasc Access 2017; Nov 11. [Epub ahead of print]

20) Ladenheim ED. Failed MILLER banding complicated by pseudoaneurysm: report of a case. Semin Dial 2015; 28 : 450-2.

21) Rokošný S, Baláž P, Wohlfahrt P, et al. Reinforced aneurysmorrhaphy for true aneurysmal haemodialysis vascular access. Eur J Vasc Endovasc Surg 2014; 47: 444-50.

22) Goel N, Miller GA, Jotwani MC, et al. Minimally Invasive Limited Ligation Endoluminal-assisted Revision (MILLER) for treatment of dialysis access-associated steal syndrome. Kidney Int 2006; 70: 765-70.

23) Shintaku S, Kawanishi H, Moriishi M, et al. Modified MILLER banding procedure for managing high-flow access and dialysis-associated steal syndrome. J Vasc Access 2015; 16: 227-32.

24) Rivers SP, Scher LA, Veith FJ. Correction of steal syndrome 
secondary to hemodialysis access fistulas: a simplified quantitative technique. Surgery 1992; 112: 593-7.

25) Vaes RHD, van Loon M, Vaes SMM, et al. One-year efficacy of the RUDI technique for flow reduction in high-flow autologous brachial artery-based hemodialysis vascular access. J Vasc Access 2015; 16 Suppl 9: 96-101.

26) Schanzer H, Schwartz M, Harrington E, et al. Treatment of ischemia due to "steal" by arteriovenous fistula with distal artery ligation and revascularization. J Vasc Surg 1988; 7: 770-3.

27) Bourquelot P, Gaudric J, Turmel-Rodrigues L, et al. Proximal radial artery ligation (PRAL) for reduction of flow in autogenous radial cephalic accesses for haemodialysis. Eur J Vasc
Endovasc Surg 2010; 40: 94-9.

28) Bourquelot P, Gaudric J, Turmel-Rodrigues L, et al. Transposition of radial artery for reduction of excessive high-flow in autogenous arm accesses for hemodialysis. J Vasc Surg 2009; 49: 424-8.

29) Regalado S, Navuluri R, Vikingstad E. Distal revascularization and interval ligation: a primer for the vascular and interventional radiologist. Semin Intervent Radiol 2009; 26: $125-9$.

30) Tynan-Cuisinier GS, Berman SS. Strategies for predicting and treating access induced ischemic steal syndrome. Eur J Vasc Endovasc Surg 2006; 32: 309-15. 